\title{
Inappropriate Drug Use and Risk of Transition to Nursing Homes Among Community-Dwelling Older Adults
}

\author{
llene H. Zuckerman, PharmD, PhD*, Patricia Langenberg, $\mathrm{PhD}^{\dagger}$, Mona Baumgarten, $\mathrm{PhD}^{\dagger}$, \\ Denise Orwig, $\mathbf{P h D}^{\dagger}$, Patricia J. Byrns, MD ${ }^{\ddagger}$, Linda Simoni-Wastila, RPh, $\mathbf{P h D}^{*}$, and Jay \\ Magaziner, MSHyg, $\mathrm{PhD}^{\dagger}$ \\ *Department of Pharmaceutical Health Services Research, University of Maryland School of \\ Pharmacy, Baltimore \\ tDepartment of Epidemiology and Preventive Medicine, University of Maryland School of \\ Medicine, Baltimore \\ ¥School of Medicine, University of North Carolina at Chapel Hill
}

\section{Abstract}

Background-Adverse events from inappropriate medications are preventable risk factors for nursing home admissions.

Objective-We sought to investigate the relationship between inappropriate medications in older adults and transitions to nursing home.

\begin{abstract}
Methods-A retrospective cohort of Medicare beneficiaries with employer-sponsored supplemental health insurance was analyzed using a longitudinal data set of Medicare supplemental insurance claims. After a baseline year with no nursing home admissions, subjects were followed until the first month of transition to nursing home, loss to follow-up, or the end of the 24-month follow-up period. Survival analysis was used to compare the risk of nursing home transition among those with and without inappropriate drug use in the previous 3 months.
\end{abstract}

Results-Of the 487,383 subjects in the cohort, 22,042 (4.5\%) had a nursing home admission. Use of inappropriate drugs was associated with a $31 \%$ increase in risk of nursing home admission, compared with no use of inappropriate drugs (adjusted relative risk 1.31, 99\% confidence interval [CI] 1.26-1.36). Analyses of individual drug classes showed the risk of nursing home admission was similar, or lower, for inappropriate drugs versus other drugs of the same class. For example, the relative risk of nursing home admission was 2.34 (99\% CI 2.20-2.47) for inappropriate narcotics and 2.68 (99\% CI 2.55-2.82) for other narcotics, compared with no narcotic use.

Conclusion-Inappropriate drug use was associated with increased risk of nursing home transition, but the increased risk may be explained by underlying patient conditions for which the drugs were prescribed rather than the inappropriate drug.

\section{Keywords}

elderly; drug utilization; cohort study; nursing home admission; transitions

\footnotetext{
Copyright (C) 2006 by Lippincott Williams \& Wilkins

Reprints: Ilene H. Zuckerman, PharmD, PhD, Associate Professor, Department of Pharmaceutical Health Services Research, University of Maryland School of Pharmacy, Saratoga Garage and Offices, 220 Arch Street, Office Level 1, Baltimore, MD 21201. izuckerm@rx.umaryland.edu.

Presented at the 2005 Gerontological Society of America Annual Meeting, Orlando, Florida.
} 
Admission to a nursing home is a sentinel event for older adults. It marks a major transition from community-based living, often in the comfort of one's home, to an institutionalized setting. Older individuals with functional and cognitive deficits have the greatest likelihood of nursing home admissions. ${ }^{1,2}$ Although much is known about risk factors for nursing home admission, many of these factors cannot be intervened upon. One potentially modifiable factor is a decline in health and function due to an adverse drug event.

Compared with their younger counterparts, older adults are at significantly higher risk for medication-related adverse events. Explanations for this higher risk among elders include increased incidence and prevalence of comorbid conditions; increased use of prescribed and alternative medications; greater susceptibility to drug- disease, drug-nutrient, and drugdrug interactions; psychosocial and cognitive changes that may affect treatment adherence; lack of coordination among prescribers; and lack of pharmacology and therapeutics knowledge specific to geriatrics. ${ }^{3-5}$ Together, these factors may lead to inappropriate medication use by the patient, inappropriate prescribing by the health care professional, and inadequate monitoring. Inappropriate medication use and subsequent adverse events are potentially preventable risk factors for elders transitioning from independent living situations to long-term care, acute care hospital and other dependent environments. However, little is known about the relationship between inappropriate medication use and transitions to nursing homes.

Inappropriate medication use has been defined as the use of medications that should be entirely avoided, medications that should be avoided at excessive dosages, and medications that should not be used for excessive durations of treatment. ${ }^{6,7}$ Inappropriate medication use has been measured using various approaches, such as drug utilization review, ${ }^{8-16}$ the Medication Appropriateness Index ${ }^{17}$ and "drugs-to-avoid" criteria (eg, Beers' criteria). ${ }^{6,7,18}$ Of all the various criteria used to evaluate medication prescribing appropriateness, the most widely used and accepted are the criteria developed by Beers. ${ }^{6,7,18}$ One advantage of the Beers criteria is that they can be applied to populations using pharmacy claims and that they require minimal clinical information. A disadvantage is that when used alone, Beers criteria do not include the richness of information obtained from a medical record review.

There is an informative body of descriptive analyses on medication use in the elderly, including prevalence of potentially inappropriate use. Specifically, much research has been published on the extent of use of medications that should be entirely avoided in the elderly. ${ }^{6,7,18-24}$ However, there is a lack of empirical studies of the relationship between medication use factors and health outcomes. ${ }^{8,25-27}$ Thus, the objective of this study was to estimate the association between inappropriate medication use and transitions from independent to dependent care environments in older adults.

\section{Methods \\ Data Source}

The MarketScan Medicare Supplemental and Coordination of Benefits database was used for the analyses. The database, produced by Thomson Medstat, contains information on a convenience sample of privately insured individuals who are covered by employersponsored Medicare supplemental benefit plans. Employers who contribute data to the MarketScan database are generally self-insured. The longitudinal database links medical and prescription drug administrative claims with person-level enrollment data.

\section{Study Design}

A retrospective cohort design was used. A cohort was assembled from 3 years (2000, 2001, and 2002) of MarketScan data. Subjects were included in the analysis if they were age 65 
years and older and had 1 year of eligibility with no nursing home admissions; the first full year of eligibility was the subject's baseline period. Because the exposure variable is based on measuring prescription drug use, subjects without any prescription coverage were excluded, and periods of observation without supplemental insurance and prescription drug coverage were excluded. Subjects were followed until their first admission to a nursing home after the 1-year baseline period, loss to follow-up or the end of the study period (December 31, 2002). Thus, subjects were followed for a maximum of 24 months after their 1 -year baseline period.

\section{Measures}

The outcome in this study was transition to a nursing home, which was measured during each person-month of observation. The exposure of interest was drug use. Because drug use can vary over the course of time, drug use variables were treated as time-dependent. Measures for potentially inappropriate medication use were developed at the person-month level. Potentially inappropriate medications were defined using criteria developed by Beers and others ${ }^{6,7,18}$ using the most recently updated list of potentially inappropriate medications. ${ }^{18} \mathrm{~A}$ variable was created for each person, for each month, for each potentially inappropriate drug (eg, chlordiazepoxide) and for each drug category (eg, long-acting benzodiazepines), which resulted in 74 potentially inappropriate drugs, and 21 potentially inappropriate drug classes. A variable was also created reflecting the monthly count of any potentially inappropriate drug for each person.

In addition to person-month counts of potentially inappropriate drugs, additional personmonth drug use variables were created: a variable reflecting the count of any prescription drug and a variable for the count of any prescription that was not considered inappropriate (ie, "other drugs"). Thus, the sum of the monthly inappropriate drug and other drug counts equaled the total monthly prescription drug count. Finally, to have clinically meaningful reflections of drug prescribing prior to nursing home admission or censorship (ie, loss to follow-up or December 2002, whichever occurred first), the monthly measures of drug use were used to calculate rolling counts of previous 3-month use at each month, which were used in the models as the prior drug use variables.

Other measures included in the analysis were potential confounders of the association between medication use and nursing home transition, including sociodemographic variables, comorbidities and previous hospitalization. Dementia and depression were included because they have been found to be associated with nursing home admission. ${ }^{28}$ Additionally, as a measure of overall health status and comorbidity, the Diagnostic Cost Group/Hierarchical Coexisting Condition (DCG/HCC) tool, a risk adjuster derived from Medicare claims, was used to control for comorbidities during the baseline period. The DCG/HCC is the basis for the "selected significant disease model" that the Centers for Medicare and Medicaid Services have used to set capitation rates for Medicare HMOs since January $2004 .{ }^{29}$ This model created indicators for the presence of 189 medical conditions. The risk adjuster then applies previously calibrated weights to approximately 100 of these conditions to create a summary score of the patient's expected Medicare expenditure under Parts A and B for the following year. The application of the DCG/HCC model used the 12 months of baseline inpatient and outpatient claims to create a predicted value for services in the immediate postadmission year for each study subject. As an additional measure of health status, a variable indicating employment status (actively working full or part time versus retired) was included. Previous hospital utilization is also a strong predictor of future nursing home use, so a variable expressing the number of hospital admissions during the 1 year baseline period was created for use in the modelbuilding strategy. 


\section{Statistical Analysis}

A continuous time proportional hazards model for interval-censored data was used to estimate the association between nursing home transition and inappropriate drug use. Selection of the model was based on several considerations. First, since data on each individual may be incomplete (eg, periods of insurance ineligibility), survival analysis was used to allow for inclusion of all available data with censoring of subjects lacking complete data. A second data issue is the use of interval-censored data. This means that the outcome is known to have occurred during a particular interval of time, in this case, the month. The Cox proportional hazards model does not adequately handle interval-censored data. A maximum likelihood method with a complementary log-log link for the linear model was used which allows for time-varying explanatory variables and also efficiently handles large numbers of ties and large datasets. ${ }^{30,31}$ The regression coefficient estimates can be interpreted as logrelative hazards, such that the exponentiated coefficients have a relative risk interpretation, similar to the Cox model coefficients. This method requires that each individual have only 1 event. Thus, to use the patient as the unit of analysis and to maintain independence of observations, the first admission was modeled. Using this method, a multivariable model was developed to assess the association between any inappropriate drug use and nursing home admission. In addition, separate models were developed to assess the association between each inappropriate drug class and nursing home admission. Alpha was set at $P=$ 0.01 for determination of level of statistical significance. Relative risks (RR) and $99 \%$ confidence intervals $(\mathrm{CI})$ are reported.

Analyses comparing use of inappropriate drugs to use of no inappropriate drugs do not answer whether it is the inappropriateness of the drug that increases the risk of nursing home transition, or whether it is the use of a drug in that class (regardless of appropriateness of the specific drug) or the reason for which the drug was prescribed, that accounts for the increased risk of nursing home transition. To assess whether effects are due to confounding by indication, additional analyses were undertaken for those drug classes that had the largest effect sizes and that had other drugs available which had not been declared "inappropriate" for use in the elderly. These analyses compared class-specific inappropriate drug use to class-specific "other" drug use and to no use of drugs in the specific drug class with respect to the risk of nursing home transition. As in previous analyses, the drug use period is timedependent and is defined as use in the previous 3 months.

Power analysis and sample size estimation were performed prior to initiating the study. Assuming an alpha of 0.01 and beta of 0.1, annual incidence of nursing home admission among those without inappropriate medication use as low as $2 \%$ and the prevalence of inappropriate medication use as low as 5\%, a sample size of 450,000 provided enough power to detect a relative risk as low as 1.21 .

\section{Results}

During the years 2000 through 2002, there were 1,243,504 subjects enrolled in MarketScan Medicare Supplemental and Coordination of Benefits database. A cohort of 487,383 subjects was available for analysis after applying inclusion and exclusion criteria (Fig. 1).

On average, each subject had 20 months of follow-up during the study period, with a range of 1 to 24 months, accounting for a total of 9,384,444 person-months of observation. More than $50 \%$ of the subjects had the maximum 24 months of follow-up during the study period. Table 1 provides descriptive information on baseline covariates. The mean age was 73.8 years; $55.5 \%$ were women, and more than $75 \%$ lived in a standard metropolitan statistical area. Almost one-half of the subjects had a comprehensive Medicare supplemental insurance plan (vs. a preferred provider organization or point-of-service plan with or without 
capitation) and more than $95 \%$ were retired. Nearly $3 \%$ of the subjects had a diagnosis of dementia, and $2.1 \%$ had a depression diagnosis. Median predicted Medicare spending was $\$ 2928$ and the range was $\$ 1212$ to $\$ 57,918$.

Fewer than $14 \%$ of the subjects had no prescription drugs during the baseline year. Annual prevalence of potentially inappropriate drugs, defined as 1 or more prescriptions for any of the 74 potentially inappropriate drugs during the baseline year, was $41.9 \%$. Annual baseline prevalences for individual classes of potentially inappropriate drugs ranged from $0 \%$ to $14.0 \%$. Hormones, which include systemic estrogens and methyltestosterone, were the most prevalent of the inappropriate drug classes, with $14.0 \%$ of the cohort having a prescription. Annual prevalence of inappropriate drug use, excluding hormones, was 35.9\%. Use of potentially inappropriate analgesics (propoxyphene, meperidine and pentazocine) (10.0\%) also was high.

Of the 487,383 subjects in the cohort, 22,042 (4.5\%) experienced a nursing home transition during the 24-month study period. The 1-year cumulative incidence was 26.7 transitions per 1000 subjects.

Table 2 shows the unadjusted and adjusted risk ratios for nursing home admission for each of the covariates, including the exposure of interest, any inappropriate drug. All variables remained significant after adjustment, although the effects were attenuated. A $31 \%$ increase in risk of transition was identified among subjects with any inappropriate drug use during the previous 3 months, as compared with subjects without any inappropriate drugs (Table 2, adjusted RR 1.31, 99\% CI 1.26-1.36). Use of any other drug (ie, drugs not considered inappropriate) was also associated with nursing home transition.

Table 3 displays unadjusted and adjusted relative risks of nursing home transition for each class of inappropriate drugs). In the adjusted models for individual drug classes, hormones were the only drug class with a significant protective effect on nursing home transition (adjusted RR 0.74, 99\% CI 0.68-0.80). Antipsychotics, antiemetics and analgesics exhibited the strongest effect, with relative risks ranging from 1.97 to 2.03 .

Because of the controversy surrounding the risks and benefits of hormone replacement therapy in postmenopausal women and of the observed protective effect on nursing home transition, additional analyses were performed excluding hormones as a potentially inappropriate drug. The use of potentially inappropriate drugs, excluding hormones, remained a significant risk factor for nursing home transition (adjusted RR 1.45, 99\% CI $1.40-1.51)$.

To further explore the association of potentially inappropriate drug use and nursing home transition, additional analyses were undertaken for the 3 classes of drugs with the largest effect sizes (ie, narcotic analgesics, antiemetics and antipsychotics). The adjusted relative risks are shown in Table 4. For narcotic analgesics and antiemetics, the risk of nursing home transition was similar for inappropriate drugs and other drugs. Inappropriate narcotic analgesics included propoxyphene, meperidine and pentazocine. All other narcotic analgesics were considered to be alternatives to the inappropriate narcotic analgesics. Both inappropriate and alternative narcotic analgesic drug use, compared with no narcotic analgesic drug use, were associated with about a 2.5 -fold increased risk of nursing home transition. The relative risk of other narcotic analgesics was statistically significantly higher than inappropriate narcotic analgesics (RR 1.15, 99\% CI 1.07-1.23).

Similarly, for antiemetic drug use each person-month was categorized with regard to antiemetic use during the previous 3 months: inappropriate antiemetics, other antiemetics and no antiemetics, with this last group as the reference category. There was only 1 
antiemetic, trimethobenzamide, which was considered inappropriate. Other antiemetics included dimenhydrinate, dolasetron, dronabinol, granisetron, meclizine, metoclopramide, ondansetron, prochlorperazine and triethylperazine. Both inappropriate and other antiemetic use, compared with no antiemetic use, were associated with about a 2-fold increased risk of nursing home transition, with no statistically significant difference between inappropriate and other antiemetics.

The risk associated with other antipsychotic drugs was greater than that of inappropriate antipsychotic drugs (Table 4). Two antipsychotics, mesoridazine and thioridazine, were considered to be potentially inappropriate in the elderly. Other antipsychotics included: aripiprazole, chlorpromazine, clozapine, droperidol, fluphenazine, haloperidol, loxapine, molindone, olanzapine, perphenazine, pimozide, prochlorperazine, quetiapine, risperidone, thiothixene, trifluoperazine, and ziprasidone. Other antipsychotic use was associated with a more than 4-fold increase in the risk of nursing home transition (adjusted RR 4.25, 99\% CI 3.98-4.54) whereas inappropriate antipsychotics had only a 2.5 -fold increase in risk (adjusted RR 2.50, 99\% CI 1.62-3.87). The risk of nursing home admission was statistically significantly greater for other antipsychotics compared with inappropriate antipsychotics (adjusted RR 1.70, 99\% CI 1.09-2.64).

\section{Discussion}

In a large, noninstitutionalized population of Medicare beneficiaries with employersponsored supplemental health insurance, use of medications deemed to be inappropriate in the elderly was associated with a $31 \%$ increase in risk of nursing home transition. The relative risk varied by the inappropriate medication drug class, with relative risks as high as 2.0 for inappropriate analgesics, antiemetics and antipsychotics. This effect size is similar to what Lau and colleagues found when they examined the relative odds of hospitalization associated with inappropriate medication use among nursing home residents. They reported a 27\% increase in odds for hospitalization among residents who received inappropriate drug therapy, compared with those who did not receive inappropriate drug therapy in either the same month or for 2 consecutive months prior to the hospitalization. ${ }^{26}$

However, analyses of individual drug classes of inappropriate medications suggest that the association is confounded by indication, a classic issue in observational studies of drug effects. ${ }^{32}$ It was consistently found that the risk of nursing home transition was similar for inappropriate drugs and "other" drugs of the same drug class. Therefore, it may not be the "inappropriateness" of the drug that increased the risk of nursing home transition, but rather the indication for the drug itself (eg, pain and symptom control, or mental disorder). If the association is not causal, then interventions to decrease use of these inappropriate medications may not result in a decrease in incidence of nursing home transition. Hanlon and colleagues also suggested that drugs-to-avoid lists such as Beers be "accepted with caution." 8,27 Indeed, in a cohort of 3076 community-dwelling elderly, Fillenbaum, Hanlon and colleagues failed to find a statistically significant association between inappropriate drug use and nursing home admission. ${ }^{27}$ This may be attributed to their smaller sample size, use of self-reported nursing home admission and drug use rather than administrative claims data as in this study, and differences between their patient population and the MarketScan cohort.

Hormone drug use appeared to have a protective effect on nursing home transition. This may be the result of confounding by health-related factors; that is, healthier women, or women with healthy lifestyles, may be more likely to take hormone replacement therapy than less healthy women. However, the DCG/HCC as a comorbidity risk adjuster used in this study has been shown to control effectively for comorbidity confounding. ${ }^{33,34}$ It is also possible 
that hormone drug use may not be considered inappropriate, and actually provides a benefit, in some elderly women. When hormone drugs were excluded from the operational definition of inappropriate drugs, the relative risk of nursing home transition was slightly higher than when hormone drugs were included.

Incidence of nursing home transition in this community sample of Medicare beneficiaries was low. One-year cumulative incidence was $2.67 \%$. The low incidence is not surprising for several reasons. First, the sample comprised community residents for at least 10 months, so sicker, institutionalized elderly were excluded. Second, all individuals had private health insurance in addition to Medicare. On average, their income, education, and health were likely to be better than that of the general population of the same age. The low incidence found in this study was consistent, however, with other findings in similar populations. In an extensive review of the literature on outcomes in the elderly, Miller and Weissert estimated the annual incidence of nursing home admission among nondisabled community elders to be $2.9 \%$, with estimates ranging between $2.0 \%$ and $3.5 \% .35$

Annual prevalence of inappropriate drug use during the baseline year was $41.9 \%$, which is higher than in other studies using similar criteria among community-dwelling elderly. $22,23,36,37$ This is most likely explained by the way in which inappropriate drugs were operationalized. To date, there are few published studies examining prevalence of inappropriate medications using the most recently published Beers list. ${ }^{18}$ This list contains 25 additional drugs that should not be used in the elderly, of which 21 were included in this study (drugs that depended upon dose, duration or diagnosis were not included in this study). The addition of these inappropriate drugs may have accounted for the increased prevalence. Indeed, prevalence of hormone use alone was nearly $14 \%$. When hormones were excluded from the operational definition of inappropriate drugs, the annual prevalence was $35.9 \%$, which is still higher than in previously published reports. When all newly added inappropriate drugs were excluded, the annual prevalence was $28.4 \%$, which is closer to but still somewhat higher than other published estimates, which range from $21 \%$ to $25 \%$. $22,36-38$ Thus, it is possible that variation in the way inappropriate drug use was defined in this study affected the estimate of prevalence of inappropriate drug use. An alternative explanation for the higher inappropriate drug prevalence is that our study population has a higher use of inappropriate drugs. However, the prevalence of selected highly prevalent drugs (propoxyphene, amitriptyline and diazepam) was similar to that in other published estimates. ${ }^{22,23,36,37}$

Although the absolute risk of nursing home transition was low, the high prevalence of inappropriate medication use could have potentially important clinical and economic implications, if the association between inappropriate medication use and nursing home transition is indeed causal. With a relative risk of 1.31 and an inappropriate drug prevalence of $41.9 \%$, the attributable risk fraction in the population is $11.5 \%$. However, it is only valid to consider attributable risk if the association between inappropriate drug use and nursing home transition is a causal one.

This study has several strengths. The large sample size provides robustness to the conclusions, protecting against a Type 2 error. Since the outcome was a rare event, a large sample size was necessary to detect small relative risks and to produce precise estimates. Another strength of this study is the drug use measure, which was measured as a timedependent variable. This ensured that the drug exposure preceded the potential outcome and was close enough in time to be plausibly related to the potential event. This study also addressed confounding by indication by comparing the risk of nursing home admission among inappropriate drug users to users of other drugs of the same drug class. 


\section{Limitations}

Selection bias is a potential concern in this study. In a cohort study, selection bias can be viewed as unobserved confounding; not all potential confounders can be measured in this database. These unobserved variables may be correlated with nursing home admission and inappropriate drug use, thereby acting as confounders. ${ }^{39}$ Although the MarketScan database is rich with information about nursing home utilization, medication utilization, and insurance coverage information, it lacks important clinical measures of cognitive and functional status (eg, mini-mental examination, activities of daily living). In addition, it does not have data on race/ethnicity, which may be an important confounder, since white race and non-Hispanic ethnicity have been positively associated with nursing home transition ${ }^{28}$ and, in some studies, white race has been positively associated with inappropriate medication use. $^{23}$

Information bias is another threat to the internal validity of this study. In this study, prescription drug claims were used as a proxy for drug exposure. Claims databases such as MarketScan provide an efficient way to measure drug exposure, and an acceptable, reliable resource for epidemiological and other health research, ${ }^{40,41}$ and may even be considered a strength of this study, since use of prescription claims reduces potential recall bias that may arise from collection of self-report data. However, misclassification of drug exposure may occur because of medication noncompliance, or incomplete or missing data. ${ }^{41}$ For example, prescription claims do not include over-the-counter drug utilization, unless there was a prescription claim generated for coverage and payment of the over-the-counter drug, which is unusual. ${ }^{42}$ Because there is no reason to believe that misclassification of drug exposure would be different for those with and without nursing home transitions, bias would be likely towards the null. ${ }^{43}$

Finally there is questionable generalizability of results from MarketScan samples. ${ }^{44}$ Since MarketScan is a convenience sample of commercially insured elders with Medicare (and in this study, the sample was limited to those with prescription drug coverage), the population from which the MarketScan data are drawn may not be representative of all commercially insured, nor is it representative of all elderly in the United States. However, based on age, gender, and urban/rural residence, the study sample appears to be fairly representative of Medicare beneficiaries with employer-sponsored private insurance.

\section{Conclusion}

Inappropriate drug use was associated with an increased risk of nursing home transition, but the increased risk may be explained by underlying patient conditions for which the drugs were prescribed rather than the inappropriate drug, because findings at the drug class level suggest that the association may be confounded by indication. Interventions to decrease inappropriate drug use continue to be conducted without a clear understanding of what constitutes drug therapy inappropriateness. ${ }^{45,46}$ There is a tremendous need for additional research on measurement of inappropriate drug therapy that is more comprehensive than simply a list of drugs that should not be used. Thus, until there are measures with improved predictive validity, clinicians and policy makers should be cautious before investing in interventions to decrease potentially inappropriate drug use.

\section{Acknowledgments}

We thank Dr. Van Doren Hsu of Pharmaceutical Research Computing, University of Maryland School of Pharmacy, for assistance with data management. We also acknowledge Thomson Medstat for permission to access the MarketScan databases.

Dr. Zuckerman was supported by a career development grant from the National Institute on Aging (K01AG22011). 


\section{References}

1. Liu K, McBride T, Coughlin T. Risk of entering nursing homes for long versus short stays. Med Care. 1994; 32:315-327. [PubMed: 8139297]

2. Coughlin TA, McBride TD, Liu K. Determinants of transitory and permanent nursing home admissions. Med Care. 1990; 28:616-631. [PubMed: 2366601]

3. Nolan L, O'Malley K. Prescribing for the elderly. Part I: sensitivity of the elderly to adverse drug reactions. J Am Geriatr Soc. 1988; 36:142-149. [PubMed: 3276767]

4. Cadieux RJ. Drug interactions in the elderly. How multiple drug use increases risk exponentially. Postgrad Med. 1989; 86:179-186. [PubMed: 2685792]

5. Gurwitz JH, Avorn J. The ambiguous relation between aging and adverse drug reactions. Ann Intern Med. 1991; 114:956-966. [PubMed: 2024864]

6. Beers MH. Explicit criteria for determining potentially inappropriate medication use by the elderly. An update. Arch Intern Med. 1997; 157:1531-1536. [PubMed: 9236554]

7. Beers MH, Ouslander JG, Rollingher I, et al. Explicit criteria for determining inappropriate medication use in nursing home residents. Arch Intern Med. 1991; 151:1825-1832. [PubMed: 1888249]

8. Hanlon JT, Fillenbaum GG, Kuchibhatla M, et al. Impact of inappropriate drug use on mortality and functional status in representative community dwelling elders. Med Care. 2002; 40:166-176. [PubMed: 11802089]

9. Zuckerman IH, Mulhearn DM, Metge CJ. Inter- and intrarater reliability of retrospective drug utilization reviewers. J Am Pharm Assoc (Wash). 1999; 39:45-49. [PubMed: 9990187]

10. Monane M, Matthias DM, Nagle BA, et al. Improving prescribing patterns for the elderly through an online drug utilization review intervention: a system linking the physician, pharmacist, and computer. JAMA. 1998; 280:1249-1252. [PubMed: 9786375]

11. Smith DH, Christensen DB, Stergachis A, et al. A randomized controlled trial of a drug use review intervention for sedative hypnotic medications. Med Care. 1998; 36:1013-1021. [PubMed: 9674619]

12. Raisch DW, Sleath BL. Using feedback letters to influence the use of antiulcer agents in a Medicaid program. J General Intern Med. 1999; 14:145-150.

13. Rascati KL, Okano GJ, Burch C. Evaluation of physician intervention letters. Med Care. 1996; 34:760-766. [PubMed: 8709658]

14. Collins TM, Mott DA, Bigelow WE, et al. A controlled letter intervention to change prescribing behavior: results of a dual-targeted approach. Health Serv Res. 1997; 32:471-489. [PubMed: 9327814]

15. McBride JE, Pater JL, Dorland JL, et al. Extent and variation of omeprazole prescribing in an elderly population of Ontario. Ann Pharmacother. 1997; 31:411-416. [PubMed: 9101000]

16. Hennessy S, Bilker WB, Zhou L, et al. Retrospective drug utilization review, prescribing errors, and clinical outcomes. JAMA. 2003; 290:1494-1499. [PubMed: 13129990]

17. Hanlon JT, Schmader KE, Samsa GP, et al. A method for assessing drug therapy appropriateness. J Clin Epidemiol. 1992; 45:1045-1051. [PubMed: 1474400]

18. Fick DM, Cooper JW, Wade WE, et al. Updating the Beers criteria for potentially inappropriate medication use in older adults: results of a US consensus panel of experts. Arch Intern Med. 2003; 163:2716-2724. [PubMed: 14662625]

19. Aparasu RR, Mort JR. Inappropriate prescribing for the elderly: Beers criteria-based review. Ann Pharmacother. 2000; 34:338-346. [PubMed: 10917382]

20. Aparasu RR, Fliginger SE. Inappropriate medication prescribing for the elderly by office-based physicians. Ann Pharmacother. 1997; 31:823-829. [PubMed: 9220038]

21. Goulding MR. Inappropriate medication prescribing for elderly ambulatory care patients. Arch Intern Med. 2004; 164:305-312. [PubMed: 14769626]

22. Willcox SM, Himmelstein DU, Woolhandler S. Inappropriate drug prescribing for the communitydwelling elderly. JAMA. 1994; 272:292-296. [PubMed: 8028142] 
23. Zhan C, Sangl J, Bierman AS, et al. Potentially inappropriate medication use in the communitydwelling elderly: findings from the 1996 Medical Expenditure Panel Survey. JAMA. 2001; 286:2823-2829. [PubMed: 11735757]

24. Simon SR, Chan KA, Soumerai SB, et al. Potentially inappropriate medication use by elderly persons in u. s. Health maintenance organizations, 2000-2001. J Am Geriatr Soc. 2005; 53:227232. [PubMed: 15673345]

25. Gupta S, Rappaport HM, Bennett LT. Inappropriate drug prescribing and related outcomes for elderly medicaid beneficiaries residing in nursing homes. Clin Ther. 1996; 18:183-196. [PubMed: 8851462]

26. Lau DT, Kasper JD, Potter DE, et al. Hospitalization and death associated with potentially inappropriate medication prescriptions among elderly nursing home residents. Arch Intern Med. 2005; 165:68-74. [PubMed: 15642877]

27. Fillenbaum GG, Hanlon JT, Landerman LR, et al. Impact of inappropriate drug use on health services utilization among representative older community-dwelling residents. Am J Geriatr Pharmacother. 2004; 2:92-101. [PubMed: 15555485]

28. Miller EA, Weissert WG. Predicting elderly people's risk for nursing home placement, hospitalization, functional impairment, and mortality: a synthesis. Med Care Res Rev. 2000; 57:259-297. [PubMed: 10981186]

29. Pope GC, Kautter J, Ellis RP, et al. Risk adjustment of Medicare capitation payments using the CMS-HCC model. Health Care Financ Rev. 2004; 25:119-141. [PubMed: 15493448]

30. Allison, PD. Survival Analysis Using the SAS System: Theory and Application. 1st. Cary, NC: SAS Institute Inc.; 1995.

31. Prentice RL, Gloeckler LA. Regression analysis of grouped survival data with application to breast cancer data. Biometrics. 1978; 34:57-67. [PubMed: 630037]

32. McMahon AD, MacDonald TM. Design issues for drug epidemiology. Br J Clin Pharmacol. 2000; 50:419-425. [PubMed: 11069436]

33. Stuart, B.; Simoni-Wastila, L.; Chauncey, D. Health Aff (Millwood). 2005. Assessing the impact of coverage gaps in the Medicare Part D drug benefit; p. W5-167-W5-179.

34. Wrobel MV, Doshi J, Stuart BC, et al. Predictability of prescription drug expenditures for Medicare beneficiaries. Health Care Financ Rev. 2003; 25:37-46. [PubMed: 15124376]

35. Miller EA, Weissert WG. Incidence of four adverse outcomes in the elderly population: implications for home care policy and research. Home Health Care Serv Q. 2001; 20:17-47. [PubMed: 12068965]

36. Curtis LH, Ostbye T, Sendersky V, et al. Inappropriate prescribing for elderly Americans in a large outpatient population. Arch Intern Med. 2004; 164:1621-1625. [PubMed: 15302631]

37. Stuart B, Kamal-Bahl S, Briesacher B, et al. Trends in the prescription of inappropriate drugs for the elderly between 1995 and 1999. Am J Geriatr Pharmacother. 2003; 1:61-74. [PubMed: 15555468]

38. Zhan C, Correa-de-Araujo R, Bierman AS, et al. Suboptimal prescribing in elderly outpatients: potentially harmful drug-drug and drug-disease combinations. J Am Geriatr Soc. 2005; 53:262267. [PubMed: 15673350]

39. Zohoori N, Savitz DA. Econometric approaches to epidemiologic data: relating endogeneity and unobserved heterogeneity to confounding. Ann Epidemiol. 1997; 7:251-257. [PubMed: 9177107]

40. Quam L, Ellis LB, Venus P, et al. Using claims data for epidemiologic research. The concordance of claims-based criteria with the medical record and patient survey for identifying a hypertensive population. Medical Care. 1993; 31:498-507. [PubMed: 8501997]

41. Lau HS, de Boer A, Beuning KS, et al. Validation of pharmacy records in drug exposure assessment. J Clin Epidemiol. 1997; 50:619-625. [PubMed: 9180655]

42. Simon LS, Zhao SZ, Arguelles LM, et al. Economic and gastrointestinal safety comparisons of etodolac, nabumetone, and oxaprozin from insurance claims data from patients with arthritis. Clin Ther. 1998; 20:1218-1235. discussion 192-193. [PubMed: 9916614]

43. Rothman, KJ.; Greenland, S. Modern Epidemiology. 2nd. Philadelphia: Lippincott Williams \& Wilkins; 1998. 
44. Claxton AJ, Chawla AJ, Kennedy S. Absenteeism among employees treated for depression. J Occup Environ Med. 1999; 41:605-611. [PubMed: 10412102]

45. Allard J, Hebert R, Rioux M, et al. Efficacy of a clinical medication review on the number of potentially inappropriate prescriptions prescribed for community-dwelling elderly people. CMAJ. 2001; 164:1291-1296. [PubMed: 11341138]

46. Fick DM, Maclean JR, Rodriguez NA, et al. A randomized study to decrease the use of potentially inappropriate medications among community-dwelling older adults in a southeastern managed care organization. Am J Manage Care. 2004; 10:761-768. 


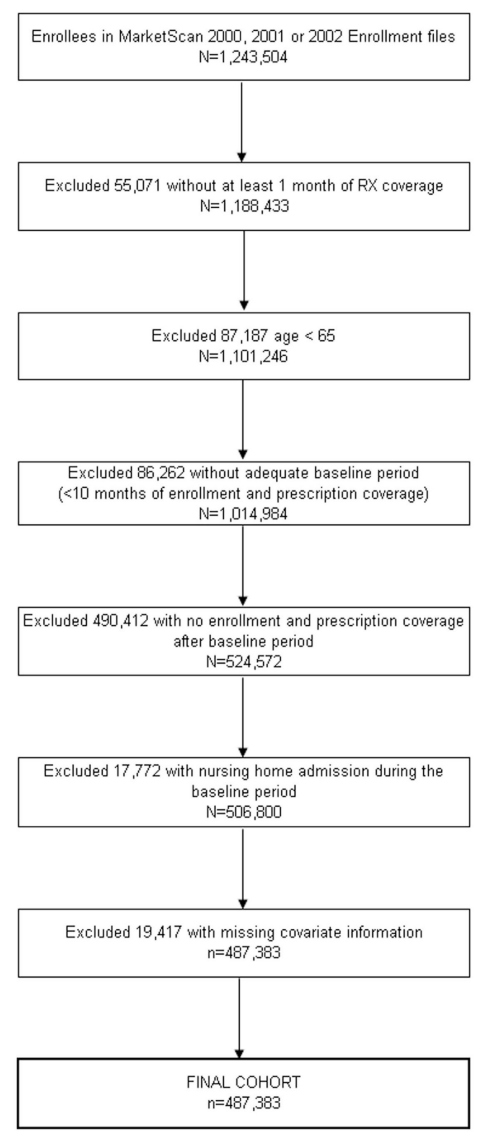

Figure 1.

Description of cohort selection, with reasons for exclusions. 
Table 1

Baseline Characteristics of the Study Cohort $(n=487,383)$

\begin{tabular}{|c|c|c|}
\hline Characteristic & $\mathbf{n}$ & Percent \\
\hline \multicolumn{3}{|l|}{ Age (years) } \\
\hline $65-69$ & 158,630 & $32.5 \%$ \\
\hline $70-74$ & 127,482 & $26.2 \%$ \\
\hline $75-79$ & 101,254 & $20.8 \%$ \\
\hline $80-84$ & 61,468 & $12.6 \%$ \\
\hline $85+$ & 38,549 & $7.9 \%$ \\
\hline \multicolumn{3}{|l|}{ Gender } \\
\hline Male & 216,964 & $44.5 \%$ \\
\hline Female & 270,419 & $55.5 \%$ \\
\hline \multicolumn{3}{|l|}{ Metropolitan statistical area } \\
\hline No & 111,583 & $22.9 \%$ \\
\hline Yes & 375,800 & $77.1 \%$ \\
\hline \multicolumn{3}{|l|}{ Geographic region } \\
\hline Northeast & 91,362 & $18.7 \%$ \\
\hline North Central & 188,446 & $38.7 \%$ \\
\hline South & 174,151 & $35.7 \%$ \\
\hline West & 33,424 & $6.9 \%$ \\
\hline \multicolumn{3}{|l|}{ Benefit plan type } \\
\hline Comprehensive & 224,136 & $46.0 \%$ \\
\hline PPO or POS without capitation & 154,870 & $31.8 \%$ \\
\hline POS with capitation & 108,377 & $22.2 \%$ \\
\hline \multicolumn{3}{|l|}{ Employment status } \\
\hline Actively working full or part time & 14,914 & $3.1 \%$ \\
\hline Retiree/other & 472,469 & $96.9 \%$ \\
\hline \multicolumn{3}{|l|}{ Dementia diagnosis } \\
\hline Yes & 14,094 & $2.9 \%$ \\
\hline No & 473,289 & $97.1 \%$ \\
\hline \multicolumn{3}{|l|}{ Depression diagnosis } \\
\hline Yes & 10,200 & $2.1 \%$ \\
\hline No & 477,183 & $97.9 \%$ \\
\hline \multicolumn{3}{|l|}{ Predicted Medicare spending (\$) } \\
\hline$\leq 2000$ & 142,187 & $29.2 \%$ \\
\hline 2000 s & 106,778 & $21.9 \%$ \\
\hline $3000 \mathrm{~s}$ & 78,274 & $16.1 \%$ \\
\hline $4000 \mathrm{~s}$ & 46,848 & $9.6 \%$ \\
\hline $5000 \mathrm{~s}$ & 30,600 & $6.3 \%$ \\
\hline $6000 \mathrm{~s}$ & 21,029 & $4.3 \%$ \\
\hline $7000 \mathrm{~s}$ & 14,664 & $3.0 \%$ \\
\hline 28000 & 47,003 & $9.6 \%$ \\
\hline
\end{tabular}




\begin{tabular}{lrr}
\hline Characteristic & n & Percent \\
\hline Previous hospitalizations (within the past year) & & \\
None & 421,929 & $86.6 \%$ \\
1 & 55,292 & $11.3 \%$ \\
$\geq 2$ & 10,162 & $2.1 \%$ \\
Total prescriptions & & \\
0 & 65,283 & $13.4 \%$ \\
$1-12$ & 105,500 & $21.6 \%$ \\
$13-24$ & 102,304 & $21.0 \%$ \\
$\geq 25$ & 214,296 & $44.0 \%$ \\
Prescriptions for potentially inappropriate drugs & & \\
0 & 283,300 & $58.1 \%$ \\
$1-12$ & 180,791 & $37.1 \%$ \\
$13-24$ & 19,599 & $4.0 \%$ \\
$\geq 25$ & 3693 & $0.8 \%$ \\
Prescriptions for other drugs & & \\
0 & 67,861 & $13.9 \%$ \\
$1-12$ & 117,488 & $24.1 \%$ \\
$13-24$ & 106,160 & $21.8 \%$ \\
$\geq 25$ & 195,874 & $40.2 \%$ \\
\hline
\end{tabular}

All characteristics were measured during the baseline year prior to the study period. PPO indicates Preferred Provider Organization; POS, Point-ofService. 
Table 2

Relative Risk (RR) of Nursing Home Admission by Drug Use and Baseline Characteristics

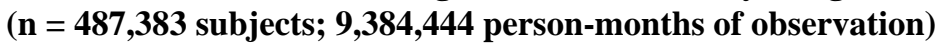

\begin{tabular}{|c|c|c|c|c|}
\hline \multirow[b]{2}{*}{ Variable } & \multicolumn{2}{|c|}{ Unadjusted } & \multicolumn{2}{|c|}{ Adjusted* } \\
\hline & $\mathbf{R R}$ & 99\% CI & $\mathbf{R R}$ & 99\% CI \\
\hline \multicolumn{5}{|c|}{ Prescriptions for potentially inappropriate drugs ${ }^{\dagger}$} \\
\hline None & 1 & referent & 1 & referent \\
\hline 1 or more & 1.45 & $1.39,1.50$ & 1.31 & $1.26,1.36$ \\
\hline \multicolumn{5}{|l|}{ Prescriptions for other drugs ${ }^{\dagger}$} \\
\hline None & 1 & referent & 1 & referent \\
\hline $1-12$ & 1.61 & $1.52,1.70$ & 1.32 & $1.24,1.40$ \\
\hline 13 or more & 3.31 & $3.11,3.52$ & 1.67 & $1.57,1.79$ \\
\hline \multicolumn{5}{|l|}{ Age (years) } \\
\hline $65-69$ & 1 & referent & 1 & referent \\
\hline $70-74$ & 2.18 & $2.02,2.35$ & 1.78 & $1.65,1.93$ \\
\hline $75-79$ & 4.43 & $4.12,4.77$ & 2.72 & $2.52,2.94$ \\
\hline $80-84$ & 8.25 & $7.67,8.86$ & 4.43 & $4.10,4.78$ \\
\hline 85 or older & 16.32 & $15.20,17.52$ & 7.72 & $7.14,8.34$ \\
\hline \multicolumn{5}{|l|}{ Gender } \\
\hline Male & 1 & referent & 1 & referent \\
\hline Female & 1.35 & $1.30,1.41$ & 1.27 & $1.22,1.32$ \\
\hline \multicolumn{5}{|l|}{ Metropolitan statistical area } \\
\hline No & 1 & referent & 1 & referent \\
\hline Yes & 1.25 & $1.20,1.31$ & 1.08 & $1.03,1.13$ \\
\hline \multicolumn{5}{|l|}{ Geographic region } \\
\hline West & 1 & referent & 1 & referent \\
\hline Northeast & 1.74 & $1.60,1.87$ & 1.55 & $1.43,1.69$ \\
\hline North Central & 1.29 & $1.19,1.40$ & 1.17 & $1.08,1.27$ \\
\hline South & 0.98 & $0.90,1.06$ & 0.97 & $0.89,1.05$ \\
\hline \multicolumn{5}{|l|}{ Benefit plan type } \\
\hline PPO or POS without capitation & 1 & referent & 1 & referent \\
\hline Comprehensive & 0.92 & $0.88,0.95$ & 0.91 & $0.86,0.95$ \\
\hline POS with capitation & 0.69 & $0.65,0.72$ & 0.81 & $0.77,0.85$ \\
\hline \multicolumn{5}{|l|}{ Employment status } \\
\hline Retiree/other & 1 & referent & 1 & referent \\
\hline Actively working & 0.22 & $0.17,0.27$ & 0.61 & $0.48,0.77$ \\
\hline \multicolumn{5}{|l|}{ Dementia diagnosis } \\
\hline No & 1 & referent & 1 & referent \\
\hline Yes & 5.32 & $5.04,5.61$ & 2.25 & $2.13,2.38$ \\
\hline \multicolumn{5}{|l|}{ Depression diagnosis } \\
\hline No & 1 & referent & 1 & referent \\
\hline
\end{tabular}




\begin{tabular}{|c|c|c|c|c|}
\hline \multirow[b]{2}{*}{ Variable } & \multicolumn{2}{|c|}{ Unadjusted } & \multicolumn{2}{|c|}{ Adjusted $^{*}$} \\
\hline & $\mathbf{R R}$ & $99 \% \mathrm{CI}$ & $\mathbf{R R}$ & 99\% CI \\
\hline Yes & 2.27 & $2.08,2.47$ & 1.25 & $1.14,1.36$ \\
\hline \multicolumn{5}{|c|}{ Predicted Medicare Spending $(\$)$} \\
\hline 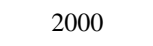 & 1 & referent & 1 & referent \\
\hline $2000 \mathrm{~s}$ & 3.32 & $3.03,3.64$ & 1.72 & $1.56,1.90$ \\
\hline $3000 \mathrm{~s}$ & 6.19 & $5.66,6.76$ & 2.27 & $2.06,2.50$ \\
\hline $4000 \mathrm{~s}$ & 8.05 & $7.34,8.83$ & 2.82 & $2.55,3.12$ \\
\hline $5000 \mathrm{~s}$ & 10.23 & $9.30,11.24$ & 3.32 & $2.99,3.69$ \\
\hline $6000 \mathrm{~s}$ & 11.93 & $10.80,13.13$ & 3.60 & $3.33,4.02$ \\
\hline $7000 \mathrm{~s}$ & 14.04 & $12.67,15.57$ & 4.07 & $3.64,4.56$ \\
\hline$\geq 8000$ & 18.73 & $17.19,20.40$ & 5.12 & $4.62,5.66$ \\
\hline \multicolumn{5}{|c|}{ Hospitalizations in the baseline year } \\
\hline None & 1 & referent & 1 & referent \\
\hline 1 & 2.27 & $2.18,2.37$ & 1.09 & $1.04,1.15$ \\
\hline 2 or more & 3.89 & $3.61,4.20$ & 1.39 & $1.28,1.50$ \\
\hline
\end{tabular}

* Adjusted for all other variables in the table.

${ }^{\dagger}$ Drug use is based on prescriptions during the previous 3 months.

PPO indicates Preferred Provider Organization; POS, Point-of-Service. 
Table 3

Relative Risk (RR) of Nursing Home Admission by Potentially Inappropriate Drug Use Therapeutic Classes $(n=487,383 ; 9,384,444$ person-months of observation)

\begin{tabular}{|c|c|c|c|c|}
\hline \multirow[b]{2}{*}{ Specific Drug Class of Inappropriate Drugs* } & \multicolumn{2}{|c|}{ Unadjusted } & \multicolumn{2}{|c|}{ Adjusted $^{\dagger}$} \\
\hline & $\mathbf{R R}$ & $99 \% \mathrm{CI}$ & $\mathbf{R R}$ & 99\% CI \\
\hline Antipsychotics & 3.48 & $2.25,5.39$ & 2.03 & $1.31,3.14$ \\
\hline Antiemetics & 3.12 & $2.29,4.28$ & 2.02 & $1.47,2.77$ \\
\hline Analgesics & 2.78 & $2.63,2.93$ & 1.97 & $1.86,2.09$ \\
\hline Skeletal muscle relaxants & 1.65 & $1.50,1.82$ & 1.52 & $1.38,1.67$ \\
\hline Antibiotics & 2.32 & $2.04,2.64$ & 1.51 & $1.33,1.72$ \\
\hline Antiarrhythmics & 2.75 & $2.48,3.05$ & 1.51 & $1.36,1.67$ \\
\hline Antidepressants & 1.63 & $1.51,1.76$ & 1.33 & $1.23,1.44$ \\
\hline Antihistamines & 1.53 & $1.41,1.65$ & 1.31 & $1.21,1.42$ \\
\hline Long-acting benzodiazepines & 1.33 & $1.18,1.49$ & 1.14 & $1.02,1.28$ \\
\hline Nonsteroidal antiinflammatory agents & 1.03 & $0.81,1.31$ & 1.10 & $0.87,1.40$ \\
\hline Vasodilators & 2.05 & $0.77,5.42$ & 1.07 & $0.40,2.83$ \\
\hline Gastrointestinal antispasmodics & 1.22 & $1.07,1.39$ & 1.06 & $0.93,1.21$ \\
\hline Amphetamines & 0.67 & $0.34,1.34$ & 1.05 & $0.53,2.09$ \\
\hline Antiplatelet drugs & 1.60 & $1.32,1.95$ & 1.04 & $0.86,1.27$ \\
\hline Antihypertensives & 1.17 & $1.08,1.28$ & 1.02 & $0.94,1.11$ \\
\hline Histamine H2-receptor antagonists & 0.94 & $0.72,1.23$ & 0.90 & $0.69,1.17$ \\
\hline Hypoglycemics & 1.25 & $0.70,2.22$ & 0.82 & $0.46,1.45$ \\
\hline Thyroid drugs & 0.99 & $0.78,1.26$ & 0.80 & $0.63,1.02$ \\
\hline Barbiturates & 0.72 & $0.54,0.98$ & 0.79 & $0.58,1.06$ \\
\hline Hormones & 0.56 & $0.52,0.60$ & 0.74 & $0.68,0.80$ \\
\hline Anxiolytics & 0.88 & $0.49,1.58$ & 0.71 & $0.40,1.29$ \\
\hline
\end{tabular}

* Prescription use is based on prescriptions during the previous 3 months. Relative risks are used to compare the use of inappropriate drugs in the drug class within the previous 3 months to no use of inappropriate drugs in the drug class within the previous 3 months.

${ }^{\dagger}$ Adjusted models are adjusted for age, gender, other drug use, metropolitan statistical area, region, insurance type, employment status, dementia, depression, predicted Medicare spending, and previous hospitalizations. 


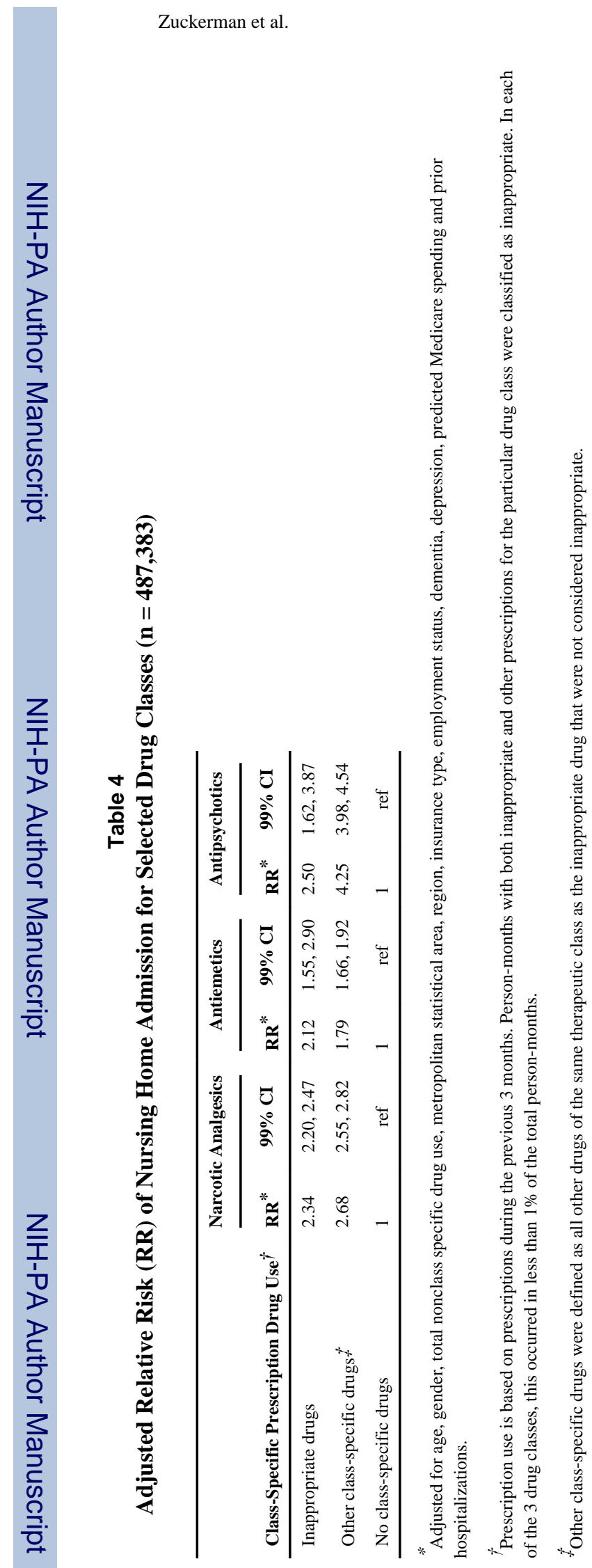

Med Care. Author manuscript; available in PMC 2013 September 11. 